\title{
Effects of vermicompost and water treatment residuals on soil physical properties and wheat yield
}

\author{
Mahmoud M. Ibrahim ${ }^{1 *}$, Essawy K. Mahmoud ${ }^{1}$, and Doaa A. Ibrahim ${ }^{2}$ \\ ${ }^{1}$ Department of Soil and Water Science, Faculty of Agriculture, Tanta University, 31527 Tanta, Egypt \\ ${ }^{2}$ Department of Soil Improvement, Institute of Soil, Water and Environment, ARC, Al-Giza, Egypt
}

Received December 28, 2014; accepted April 1, 2015

\begin{abstract}
A b s t r a c t. The application of vermicompost and water treatment residuals to improve the physical properties in the salt affected soils is a promising technology to meet the requirements of high plant growth and cost-effective reclamation. Therefore, the aim of this study was to investigate the effect of vermicompost and its mixtures with water treatment residuals on selected physical properties of saline sodic soil and on wheat yield. The treatments were vermicompost, water treatment residuals, vermicompost + water treatment residuals $(1: 1$ and $2: 1$ wet weight ratio) at levels of 5 and $10 \mathrm{~g}$ dry weight $\mathrm{kg}^{-1}$ dry soil. The considered physical properties included aggregate stability, mean weight diameter, pore size distribution and dry bulk density. The addition of vermicompost and water treatment residuals had significant positive effects on the studied soil physical properties, and improved the grain yield of wheat. The treatment of ( 2 vermicompost +1 water treatment residuals) at level of $5 \mathrm{~g} \mathrm{~kg}^{-1}$ soil gave the best grain yield. Combination of vermicompost and water treatment residuals improved the water treatment residuals efficiency in ameliorating the soil physical properties, and could be considered as an ameliorating material for the reclamation of salt affected soils.

K e y w o r d s: bulk density, pore size distribution, aggregate stability, wheat yield, vermicompost, water treatment residuals
\end{abstract}

\section{INTRODUCTION}

Soil salinity is one of the major problems for agriculture in semi arid regions, such as Egypt. Under salinity conditions, dissolved salts may accumulate in soils and inhibit plant growth. When soluble salts accumulate, $\mathrm{Na}^{+}$often becomes the dominant counter ion in the soil complex, causing the soil to become disperse. This results in a number of physical problems such as poor structure, surface crusting and poor drainage (Qadir and Schubert, 2002). The application of soil amendments to improve the physical properties

*Corresponding author e-mail: dr_3esawe@yahoo.com of salt affected soils is a promising technology to meet the requirements for high plant growth and cost-effective reclamation. Organic materials are important soil amendments in improving soil physical properties and sustaining soil productivity, particularly in arid and semi-arid regions where there is low input of organic matter. This is because the soil physical properties have a very high degree of correlation with crop production and a high influence on soil fertility and crop performance (Nnaji, 2009). Soil amendment with manures, composts, municipal biosolids and other organic wastes has been found to improve the physical and chemical properties of soil (Barzegar et al., 2002; Šimon et al., 2013; Unagwu et al., 2013). Beneficial effects of organic soil amendments include decreased soil bulk density and increased water holding capacity, aggregate stability, saturated hydraulic conductivity, water infiltration rate and biochemical activity (Martens and Frankenberger, 1992; Turner et al., 1994). Furthermore, soil aggregates can physically protect soil organic matter from biodegradation and improve the soil structure and the pore size distribution (Tisdall and Oades, 1982), all of which can affect the soil hydraulic properties. Oluwadare and Osakwe (2014) showed that the effects of organic soil amendments on soil physical properties improved by enhancing soil organic carbon status. Although several organic materials have been researched in the aspect of improving soil physical properties (Angin et al., 2013; Barzegar et al., 2002; Lordan et al., 2013; Moodley et al., 2004; Moodley and Hughes, 2006), limited literature is available on the combination of vermicompost (VC) and water treatment residuals (WTR) for improving saline-sodic soils.

(C) 2015 Institute of Agrophysics, Polish Academy of Sciences 
Vermicompost (VC) which is produced by the fragmentation of organic wastes by earthworms, contains nutrients in forms that are readily available for plant uptake (Atiyeh et al., 2000). There is good evidence that $\mathrm{VC}$ application promotes growth of plants and it has been found to have a positive effect on growth and productivity of cereals and legumes (Azarmi et al., 2008; Benik and Bejbaruah, 2004; Glenda et al., 2009; Suthar, 2006). There is an increasing interest in the potential use of $\mathrm{VC}$ as soil amendment, where the addition of $\mathrm{VC}$ improves the soil physical and chemical properties (Angin et al., 2013; Azarmi et al., 2008; Lordan et al., 2013).

Water treatment residuals (WTR) is the by-product of the production of potable water and its disposal amount is huge (Babatunde and Zhao, 2007). It was traditionally disposed to landfill but there is growing interest in applying this waste to land as an alternative disposal option (Moodley et al., 2004). WTR consists mainly of flocculated fine silt and clay, $\mathrm{Al}$ and $\mathrm{Fe}$ salts, and organic polymers which are frequently used as coagulating agents in drinking water treatment to aid settling of suspended particles and to clarify water (Ippolito et al., 2006). Previous studies have shown that the application of WTR to land as a soil amendment improved the physical soil properties by decreasing bulk density and increasing hydraulic conductivity and water retention, because of the sustained performance of the polymer in binding the silt and clay into gravel-sized aggregates. Such changes were only significant at the $1.28 \mathrm{Mg} \mathrm{ha}^{-1}$ application rate (Moodley and Hughes, 2006). Therefore, very large amounts of WTR would have to be applied in order to markedly change these inherent physical properties of soils. However, high application rate of the WTR $(>10 \%)$ causes deficiency of plant available phosphorus, which results in reducing plant growth (Dayton and Basta, 2001). Therefore, it is necessary to add fertilizer and/ or organic matter for mitigate soil P deficiencies when WTR is reused actually as a growth medium (Park et al., 2010).

The objective of this study is, therefore, to investigate the effect of VC, WTR and their mixtures at ratios of 2:1 and 1:1 wet weight (VC:WTR), on selected physical properties of saline sodic soils and on the yield of wheat (Triticum aestivum).

\section{MATERIALS AND METHODS}

Wheat (Triticum aestivum) cultivar Sakha 93 was sown in pots on November 15, 2009. Nine treatments were applied in a randomised complete blocks design with three replicates. The treatments used in this experiment were: $\mathrm{T} 0$ : Control; T1 :VC at $5 \mathrm{~g} \mathrm{~kg}^{-1} ; \mathrm{T} 2: \mathrm{VC}$ at $10 \mathrm{~g} \mathrm{~kg}^{-1}$; T3 :WTR at $5 \mathrm{~g} \mathrm{~kg}^{-1}$; T4: WTR at $10 \mathrm{~g} \mathrm{~kg}^{-1} ;$ T5 :VC + WTR (1:1) at $5 \mathrm{~g} \mathrm{~kg}^{-1} ; \mathrm{T} 6: \mathrm{VC}+\mathrm{WTR}(1: 1)$ at $10 \mathrm{~g} \mathrm{~kg}^{-1} ; \mathrm{T} 7: \mathrm{VC}+$ WTR (2:1) at $5 \mathrm{~g} \mathrm{~kg}^{-1}$; T8 : VC + WTR (2:1) at $10 \mathrm{~g} \mathrm{~kg}^{-1}$. Vermicompost used in this experiment was made of rice straw and animal wastes with earthworm species Eisenia fetida and Dendrobaena veneta. Water treatment residuals (WTR) were collected from El-Beharia, Egypt, water treatment plant. The properties of VC and WTR are illustrated in Table 1. Each pot contained $10 \mathrm{~kg}$ soil from surface soil samples $(0-30 \mathrm{~cm})$ after air-drying, crushing and passing through an $8 \mathrm{~mm}$ sieve to reflect natural soil conditions. The soil portions were uniformly mixed with the VC and WTR, and packed in plastic pots of $23 \mathrm{~cm}$ diameter and $25 \mathrm{~cm}$ height. The soil samples were collected from El-Hamoul area (31-07'N Latitude, 30-57'E Longitude, with elevation of about $6 \mathrm{~m}$ above mean sea level), Kafr El-Sheikh Governorate, Egypt. Some physical and chemical properties of the studied soil samples are presented in Table 1. Nitrogen fertilizer was added in three equal doses as $\mathrm{NH}_{4} \mathrm{No}_{3} 33.5 \% \mathrm{~N}$ at the rate of $178.6 \mathrm{~kg} \mathrm{ha}^{-1}$ and a basal dose of phosphorus was applied as super phosphate $15 \% \mathrm{P}$ at the rate of $35.7 \mathrm{~kg} \mathrm{ha}^{-1}$. The amount of irrigation water was determined by weighting the pots to raise the moisture content to the field capacity of each treatment, with the addition to $15 \%$ as leaching requirement.

Wheat plants were harvested after 140 days from sowing, when the grains were ripened. The grains were separated from the vegetative part and the yield of these two components was measured in g per pot. After wheat harvesting, a representative soil sample was taken from each pot and analyzed for selected soil physical properties.

Electrical conductivity (EC) and $\mathrm{pH}$ were determined in extract of the saturated vermicompost, WTR and soils using $\mathrm{pH}$ and conductivity meters, respectively. The cations $\left(\mathrm{Na}^{+} \mathrm{Mg}^{++}, \mathrm{Ca}^{++}, \mathrm{K}^{+}\right)$and anions $\left(\mathrm{HCO}^{3-}\right.$ and $\left.\mathrm{Cl}^{-}\right)$were determined in soil paste extract as described by Rhoades (1954). Ash content was determined in a muffle oven at $550^{\circ} \mathrm{C}$ for $8 \mathrm{~h}$, and organic matter of vermicompost was calculated as the difference between ash and dry weight $(50 \%$ of OM of compost was considered organic C) (AFNOR, 1991). Organic matter of WTR and soil was determined according to Walkely and Black rapid titration method, as outlined by Kim (1996). Organic matter of soil and WTR was calculated by multiplying the organic carbon value by 1.724 based on the assumption that organic matter contains $58 \%$ organic carbon.

Particle size distribution of the soil samples was determined using the international pipette method, as described by Kim (1996). Bulk density was determined using the core method by weighing undisturbed soil samples of a volume of $250 \mathrm{~cm}^{3}$ (Blake and Hartge, 1986).

Aggregate stability (AgSt) was determined in undisturbed soil samples using a wet sieving method (Kemper and Rosenau, 1986). Forty grams of each air dried soil sample, which passes through an $8 \mathrm{~mm}$ sieve, was transferred to the upper sieve of a set of sieves having 2.00, 1.00, 0.5 and $0.25 \mathrm{~mm}$ screen mesh, in the wet sieving apparatus, wetted by immersion and agitated for $5 \mathrm{~min}$. The fractions over each sieve, at the end of sieving, were collected and oven dried at $105^{\circ} \mathrm{C}$ for $24 \mathrm{~h}$. Correction for sand content in each aggregate was made after the fractions were dispersed 
T a b l e 1. Selected physical and chemical properties of the studied soil samples and soil amendments (vermicompost VC and water treatment residuals WTR)

\begin{tabular}{|c|c|c|c|c|}
\hline Properties & Units & $\begin{array}{c}\text { Soil } \\
(\mathrm{n}=20)\end{array}$ & $\begin{array}{c}\mathrm{VC} \\
(\mathrm{n}=3)\end{array}$ & $\begin{array}{l}\text { WTR } \\
(\mathrm{n}=3)\end{array}$ \\
\hline pH ( soil paste extracts) & & 8.56 & 7.6 & 7.62 \\
\hline $\begin{array}{l}\text { Electrical conductivity } \\
\text { (EC) }\end{array}$ & $\mathrm{dS} \mathrm{m} \mathrm{m}^{-1}$ & 25.82 & 4.65 & 3.23 \\
\hline $\mathrm{Ca}^{++}$ & meq $1^{-1}$ & 85.3 & 16.3 & 20.3 \\
\hline $\mathrm{Mg}^{++}$ & meq $1^{-1}$ & 70.2 & 12.6 & 5.3 \\
\hline $\mathrm{Na}^{+}$ & meq $1^{-1}$ & 166.5 & 20.3 & 6.3 \\
\hline $\mathrm{K}^{+}$ & meq $1^{-1}$ & 1.4 & 3.2 & 2.9 \\
\hline $\mathrm{Al}^{3+}$ & $\mathrm{mg} \mathrm{kg}{ }^{-1}$ & & & 3315 \\
\hline $\mathrm{Cl}^{-}$ & meq $1^{-1}$ & 102.0 & 31.5 & 28.8 \\
\hline $\mathrm{HCO}_{3}^{-}$ & meq $1^{-1}$ & 2.56 & 3.6 & 2.5 \\
\hline SAR & & 18.8 & 5.34 & 1.76 \\
\hline $\mathrm{CaCO}_{3}$ & $\%$ & 4.6 & & \\
\hline Organic matter $(\mathrm{OM})$ & $\%$ & 0.92 & 32.6 & 4.86 \\
\hline Bulk density (BD) & $\mathrm{g} \mathrm{cm}^{-3}$ & 1.53 & & \\
\hline Clay & $\%$ & 34.18 & & 65.7 \\
\hline
\end{tabular}

chemically. Three samples were wet-sieved per treatment. AgSt was expressed as a percentage of the total sieved sample.

The mean weight diameter $(M W D, \mathrm{~mm})$ was calculated using the following equation:

$$
M W D=\sum_{i=1}^{n} X i W i,
$$

where: $X i$ is the mean diameter of each size fraction $(\mathrm{mm})$, $W i$ is the proportion of the total sample mass in the corresponding size fraction, and $n$ is the number of samples.

Pore size distribution was calculated from the water retention curves using pressure cooker at pressures of 10 and $33 \mathrm{kPa}$, and pressure plate apparatus at $1500 \mathrm{kPa}$. The pore diameter corresponding to pressures of 10,33 and $1500 \mathrm{kPa}$ is equal to $28.4,8.62$ and $0.19 \mu$, respectively. The values of moisture content on volume basis used for calculating the percentage of quickly drainable pores (QDP): $>28.84 \mu$ diameter, slowly drainable pores (SDP): $28.84-$ $8.62 \mu$ diameter, water holding pores (WHP): 8.62-0.19 $\mu$ diameter, and fine capillary pores (FCP): $<0.19 \mu$ diameter, were determined according to De-Leenher and De-Boodt (1965). All measurements were made in triplicate.

Treatment mean differences were statistically analysed by the least significant difference (LSD 0.05) test (SAS Institue, 1996).

\section{RESULTS}

Bulk density (BD) of the studied soil was decreased significantly at $(\mathrm{p}<0.05)$ for all treatments except for the WTR alone at $5 \mathrm{~g} \mathrm{~kg}^{-1}$ soil and 5 or $10 \mathrm{~g}$ of $(1 \mathrm{VC}+1 \mathrm{WTR})$ $\mathrm{kg}^{-1}$ soil, compared to the control treatment (Table 2). The $\mathrm{VC}$ treatment recorded higher $\mathrm{BD}$ decrease than that of the WTR treatment. Treatment with $10 \mathrm{~g}$ of VC resulted in the highest BD decrease (12.5\%) in comparison to the control treatment. Data also showed that treatments with mixtures of various ratios between VC / WTR influenced differently the soil BD when compared with VC or WTR treatments alone. As shown in Table 2, the decrease of BD compared to the control treatment was in the following order of treatments: $5 \mathrm{~g}$ of $[2 \mathrm{VC}+1 \mathrm{WTR}]>10 \mathrm{~g}$ of $[2 \mathrm{VC}+1 \mathrm{WTR}]<5 \mathrm{~g}$ of $[1 \mathrm{VC}+1 \mathrm{WTR}]<10 \mathrm{~g}$ of $[1 \mathrm{VC}+1 \mathrm{WTR}]$.

The effect of soil amendments on the distribution of the different fractions of pores is given in Table 2. Pore size distribution was affected significantly at $(\mathrm{p}<0.05)$ by the treatments. The most positively affected categories of pores were the quickly-drainable pores (QDP), slowly drainable pores (SDP) and the water-holding pores (WHP). These three categories also represent major portions of soil porosity, and they are of a very important significance in soil fertility and plant growth. 
T a b l e 2. Effect of vermicompost and its mixtures with water treatment residuals on soil bulk density (BD) and pore size distribution after harvest of wheat crop

\begin{tabular}{|c|c|c|c|c|c|}
\hline \multirow{2}{*}{ Treatment } & \multirow{2}{*}{$\mathrm{BD}\left(\mathrm{g} \mathrm{cm}^{-3}\right)$} & \multicolumn{4}{|c|}{ Pore size distribution (\%) } \\
\hline & & QDP & SDP & WHP & FCP \\
\hline T0 & $1.52 \mathrm{a}$ & $21.36 \mathrm{c}$ & $14.54 \mathrm{~b}$ & $25.38 \mathrm{~d}$ & $38.70 \mathrm{a}$ \\
\hline $\mathrm{T} 1$ & $1.42 \mathrm{~b}$ & $30.69 \mathrm{ab}$ & $24.00 \mathrm{ab}$ & $26.85 \mathrm{~cd}$ & $18.46 \mathrm{~b}$ \\
\hline $\mathrm{T} 2$ & $1.33 \mathrm{~b}$ & $25.96 \mathrm{~b}$ & $21.99 \mathrm{ab}$ & $35.75 \mathrm{a}$ & $16.30 \mathrm{~b}$ \\
\hline $\mathrm{T} 3$ & $1.46 \mathrm{a}$ & $30.12 \mathrm{ab}$ & $24.12 \mathrm{ab}$ & $26.73 \mathrm{~cd}$ & $19.02 \mathrm{~b}$ \\
\hline $\mathrm{T} 4$ & $1.42 \mathrm{ab}$ & $32.39 \mathrm{a}$ & $26.74 \mathrm{a}$ & $23.12 \mathrm{e}$ & $17.74 \mathrm{~b}$ \\
\hline $\mathrm{T} 5$ & $1.48 \mathrm{a}$ & $32.68 \mathrm{a}$ & $19.53 \mathrm{ab}$ & $28.91 \mathrm{bc}$ & $18.89 \mathrm{~b}$ \\
\hline T6 & $1.51 \mathrm{a}$ & $30.94 \mathrm{ab}$ & $23.30 \mathrm{ab}$ & $26.73 \mathrm{~cd}$ & $19.02 \mathrm{~b}$ \\
\hline $\mathrm{T} 7$ & $1.30 \mathrm{~b}$ & $26.15 \mathrm{~b}$ & $24.05 \mathrm{ab}$ & $30.98 \mathrm{~b}$ & $19.03 \mathrm{~b}$ \\
\hline $\mathrm{T} 8$ & $1.41 \mathrm{ab}$ & $30.22 \mathrm{ab}$ & $24.50 \mathrm{~b}$ & $27.47 \mathrm{~cd}$ & $17.81 \mathrm{~b}$ \\
\hline $\mathrm{LSD}_{0.05}$ & 0.08 & 3.89 & 7.17 & 2.05 & 3.91 \\
\hline
\end{tabular}

QDP - quickly drainable pores, SDP - slowly drainable pores, WHP - water-holding pores, FCP - fine capillary pores. T0 - control, $\mathrm{T} 1-\mathrm{VC}$ at $5 \mathrm{~g} \mathrm{~kg}^{-1}$; T2 - VC at $10 \mathrm{~g} \mathrm{~kg}^{-1}$; T3 - WTR at $5 \mathrm{~g} \mathrm{~kg}^{-1}$; T4 - WTR at $10 \mathrm{~g} \mathrm{~kg}^{-1}$; T5 - VC + WTR (1:1) at $5 \mathrm{~g} \mathrm{~kg}^{-1}$; $6-\mathrm{VC}+$ WTR (1:1) at $10 \mathrm{~g} \mathrm{~kg}^{-1}$; T7 - VC + WTR (2:1) at $5 \mathrm{~g} \mathrm{~kg}^{-1}$; T8 - VC + WTR (2:1) at $10 \mathrm{~g} \mathrm{~kg}^{-1}$. The same letter do not differ significantly $(\mathrm{p}<0.05)$.

The addition of soil amendments increased significantly at $(\mathrm{p}<0.05)$ the quickly drainable pores (QDP) compared to the control (Table 2). The obtained data indicated that vermicompost addition at levels of $5 \mathrm{~g} \mathrm{~kg}^{-1}$ soil and $10 \mathrm{~g}$ $\mathrm{kg}^{-1}$ soil increased the QDP by 43.67 and $21.53 \%$ compared to the control treatment, respectively. The increments of the QDP upon the addition of $5 \mathrm{~g} \mathrm{~kg}^{-1}$ soil and $10 \mathrm{~g} \mathrm{~kg}^{-1}$ soil WTR were 41.01 and $51.63 \%$, respectively, compared to the control treatment. These results indicate that increasing the levels of vermicompost resulted in lower QDP value. Inversely, the highest values of QDP were obtained with the highest application level of $10 \mathrm{~g} \mathrm{~kg}^{-1}$ soil of WTR. Moreover, the differences between the high levels of the added $\mathrm{VC}$ and the control treatment are statistically significant. On the other hand, the difference between the low and high level of the added WTR is not statistically significant. The QDP in the pots treated with the WTR and VC combinations at two levels were enhanced when compared to $\mathrm{VC}$ alone.

The slowly drainable pore (SDP) was increased significantly for all treatments except for treatments with WTR and VC at the level of 5 of (1 VC+1 WTR) $\mathrm{kg}^{-1}$ soil (Table 2). The highest increment in SDP (84\%) over the control was

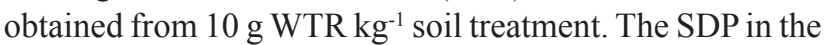
soil treated with the WTR and VC combinations at two levels was not significantly different from the other treatments.

Mean values of water holding pore (WHP) increased significantly for all soil amendment treatments as compared to the control (Table 2). The highest increment in WHP (41\%) over the control was obtained from $10 \mathrm{~g} \mathrm{VC} \mathrm{kg}^{-1}$ soil treatment, whereas the lowest WHP value was observed at $10 \mathrm{~g}$ WTR $\mathrm{kg}^{-1}$ soil treatment. Increasing VC application from 5 to $10 \mathrm{~g} \mathrm{~kg}^{-1}$ soil increased WHP by $33.15 \%$, whereas the increase of WTR from 5 to $10 \mathrm{~g} \mathrm{~kg}^{-1}$ soil decreased WHP by $15.61 \%$.

The addition of soil amendments and their mixture treatments decreased significantly, at $p<0.05$, the FCP as compared to the control (Table 2). At the same time, there is no significant difference among all the treatments and between each other. The decrement in FCP ranged from $50.82 \%$ at $5 \mathrm{~g}(2 \mathrm{VC}+1 \mathrm{WTR})$ to $57.88 \%$ at level $10 \mathrm{~g} \mathrm{VC}$ $\mathrm{kg}^{-1}$ soil. Combinations of VC with WTR at levels of 5 or $10 \mathrm{~g} \mathrm{~kg}^{-1}$ soil had no significant effect on the FCP when compared to $\mathrm{VC}$ treatment alone.

The addition of VC and WTR and their mixture treatments increased significantly, at $\mathrm{p}<0.05$, the AgSt as compared to the control (Fig. 1). However, the increment of the AgSt resulting from the addition of VC and WTR combination was not significant. Increasing the VC application rate from 5 to $10 \mathrm{~g} \mathrm{~kg}^{-1}$ soil increased the AgSt by 31.27 and $48.84 \%$, respectively, when compared to the control treatment. The highest increment in AgSt (63.4\%) over the control was obtained from $10 \mathrm{~g} \mathrm{WTR} \mathrm{kg}^{-1}$ soil treatment. The AgSt in the soil treated with the WTR and VC combinations at two levels was not significantly different from the other treatments.

As shown in Fig. 1, the effect of the soil amendment additions on the MWD had the same trend as that on the AgSt. Values of MWD increased significantly, at $p<0.05$, 


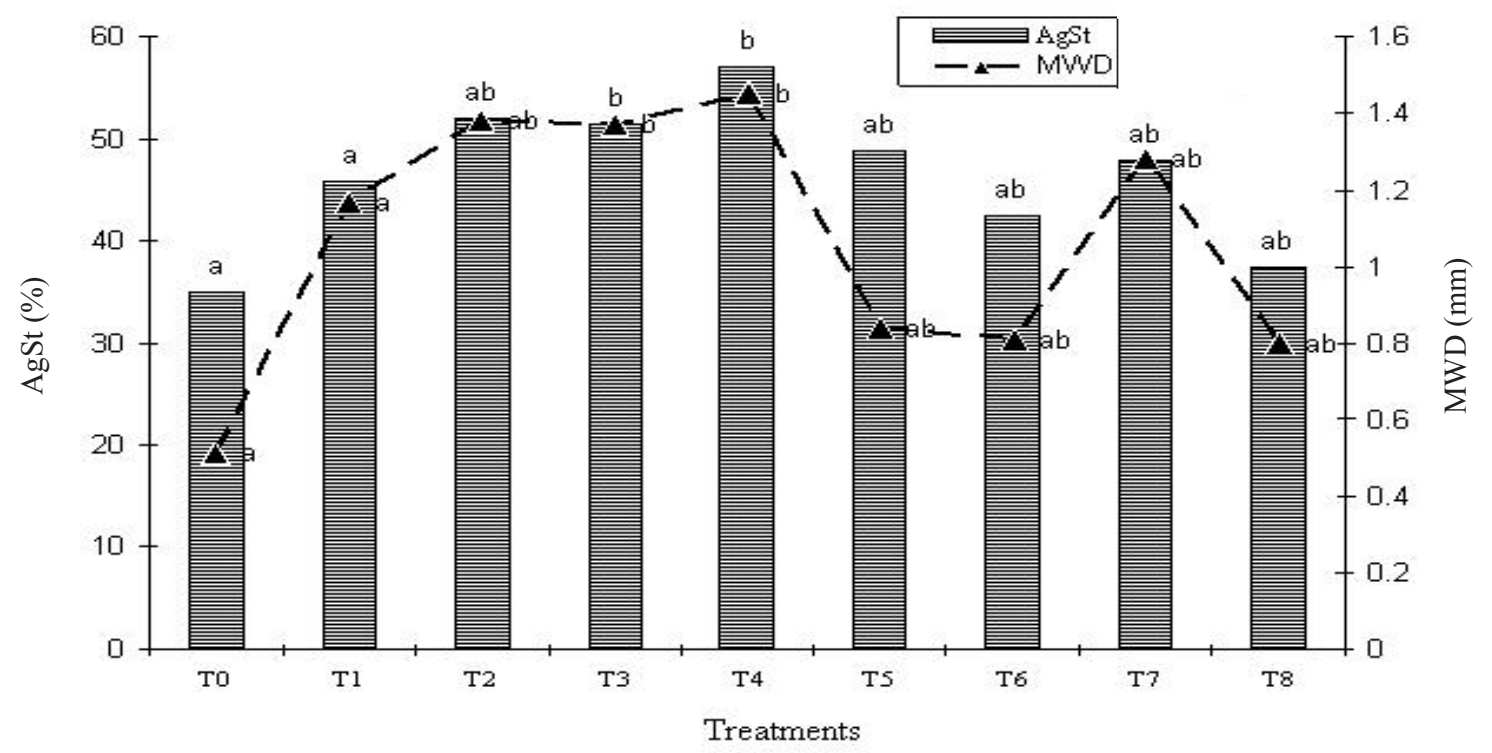

Fig. 1. Effect of vermicompost and its mixtures with water treatment residuals on aggregate stability (AgSt) and mean weight diameter (MWD) of the soil after harvest of wheat crop. Explanations as in Table 2.

by 168 and $184 \%$ upon the addition of 5 and $10 \mathrm{~g}$ WTR $\mathrm{kg}^{-1}$ soil, respectively, as compared to the control treatment, whereas the increment of MWD values upon the addition of 5 and $10 \mathrm{~g} \mathrm{~kg}^{-1}$ soil was 129 and $170 \%$ for $\mathrm{VC}$, respectively, as compared to the control treatment. For the $\mathrm{VC} / \mathrm{WTR}$ mixture treatments, the increase of MWD values was not significantly different $(\mathrm{p}<0.05)$ as compared to the $\mathrm{VC}$ alone.

The application of WTR and VC increased significantly the straw and grain yield of wheat plants at levels of 5 and $10 \mathrm{~g} \mathrm{~kg}^{-1}$ soil, compared with the control (Fig. 2). Straw weight increased by 40.37 and $31.19 \%$ for the applications of $10 \mathrm{~g}$ of WTR and VC kg-1 soil, respectively. The grain yield of wheat plants ranged between 8.5 and $14 \mathrm{~g}^{\mathrm{g}} \mathrm{pot}^{-1}$. The highest straw weight and grain yield of wheat plants was observed across all treatments with the addition of $10 \mathrm{~g}$ WTR $\mathrm{kg}^{-1}$ soil and $5 \mathrm{~g}(2 \mathrm{VC}+1 \mathrm{WTR}) \mathrm{kg}^{-1}$ soil treatments, respectively. The grain yield decreased with the addition of WTR at $5 \mathrm{~g} \mathrm{~kg}^{-1}$ soil compared with the levels of $10 \mathrm{~g} \mathrm{~kg}^{-1}$ soil. The straw weight and grain yield of wheat plants did not differ significantly among the treatments (Fig. 2).

\section{DISCUSSION}

Bulk density is an index showing soil compaction level, as compaction alone refers to process and inferring root ability. A decrement in BD means an improvement of the

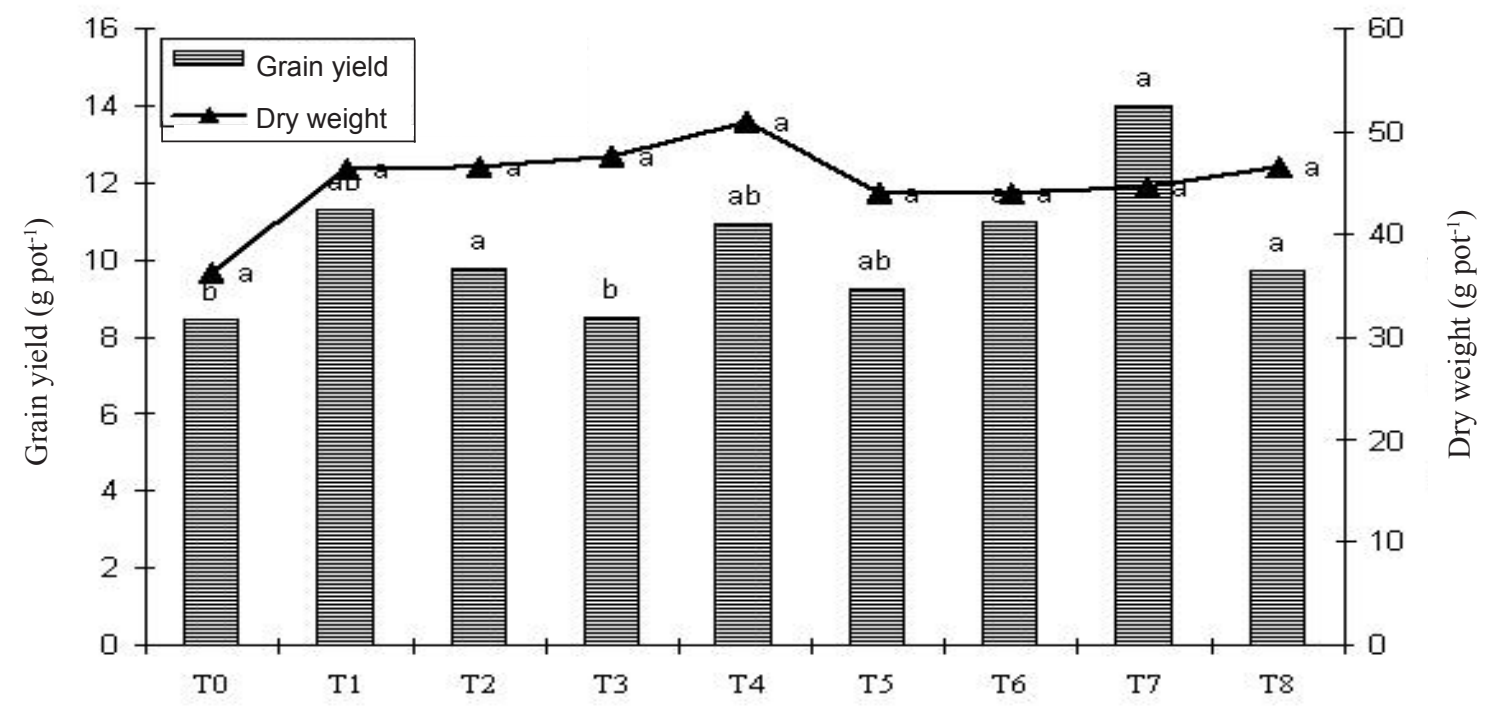

Fig. 2. Effect of vermicompost and its mixtures with water treatment residuals on wheat dry weight and grain yield. Explanations as in Table 2. 
structural status. The obtained results showed that the values of $\mathrm{BD}$ decreased significantly at $\mathrm{p}<0.05$, compared to the control treatment, upon the addition of $\mathrm{VC}$ and its mixtures with WTR. The significant decrease in the soil $\mathrm{BD}$ upon the addition of the organic amendments (VC and WTR) could be attributed to the fact that organic matter possesses low BD and could therefore reduce soil BD and compaction level as compaction alone refers to process, which leads to the increase of the soil aggregate stability (Mbah and Onweremadu, 2009). These results are in agreement with those of Smith et al. (2000) and Kalantari et al. (2010) who found that soil BD decreased under the effect of compost and vermicompost applications. These obtained results indicate that the application of $\mathrm{VC}$ with WTR improved the values of BD. However, WTR application alone exhibited no clear effect on $\mathrm{BD}$, especially at low levels. Higher mixing rates and ratios of vermicompost with WTR, $5 \mathrm{~g}$ of ( $2 \mathrm{VC}+1 \mathrm{WTR}) \mathrm{kg}^{-1}$ soil, improved the unfavourable effect of the WTR on soil BD. In general, the decrement in BD means the improvement of the structural status, water retention, plant available water, root penetration and nutrient uptake, which leads to improved wheat yield.

The obtained results showed that the addition of amendment treatments increased the pore size distribution (QDP, SDP and WHP), decreased fine capillary pores (FCP), and resulted in a better structure. These findings are in agreement with the early findings of Pagliai et al. (1981) who found that the number of small and medium sized pores increased in organic amended soils, indicating a better structure and potential plant growth. Moodley and Hughes (2006) pointed out that WTR, when added to soils, changes the pore size distribution, particularly the macro porosity. These occurred at the $1.28 \mathrm{Mg} \mathrm{ha}^{-1}$ application rate. Therefore, very large amounts of WTR would have to be applied in order to markedly change the inherent physical properties of the soil. Data also should that the addition of VC to the WTR with different ratios enhanced the increase of soil QDP when compared to VC alone. This may be due to macroporosity increase and capillary porosity decrease of the WTR by the addition of vermicompost (Seok-Gon et al., 2010).

The increase of water stable aggregates upon the addition of the VC and WTR combinations represents the effect of the amendment treatments on building good soil aggregates and conserving the aggregate stability, at the same time this helps increase the soil potential to improve other physical properties. The addition of VC and WTR and their mixture treatments increased significantly, at $p<0.05$, the $\mathrm{AgSt}$ as compared to the control. The influence of the WTR in increasing the AgSt was high at the higher application of WTR. Aggregates of WTR have high stability due to the tenacity with which the alum that was added during the water treatment process binds silt and clay. The sustained performance of aluminium sulphate (alum) in binding silt and clay enhances gravel-sized aggregates. Accordingly, aggregate stability was higher in the soil treated with the WTR than with vermicompost. These results are in agreement with Moodley and Hughes (2006).

Increases of aggregate stability in a soil are important for sustainable good soil structure. High aggregate stability allows movement of water through the soil, movement of air into and out of the soil, ease of penetration by roots, and protects the soil against erosion. These processes encourage water to flow down and to leach the salt out of the root zone as a main step of salt affected soil reclamation. Combination of VC and WTR amendments would have assisted increasing aggregate stability in the present study due to increases in soil organic matter content.

The results indicate that increasing ratios of the applied VC and WTR increased the MWD values and that the effect of the WTR on increasing MWD was more pronounced than that of the VC. Similar results were obtained by Romina et al. (2011) who pointed out that MWD increased linearly with increasing rates of the applied VC. The improved aggregate stability and MWD, upon the addition of the soil amendments, is an indicator of enhanced soil physical properties, which would be conducive for some soil microorganisms and other chemical reactions necessary for optimal plant growth. Organic soil amendments could help conserve and/or enhance the structure, because organic matter is considered an active agent that promotes aggregation through physical and chemical mechanisms (Caravaca et al., 2002). Organic matter is of major importance for the stabilisation of aggregates (Six et al., 2004). Grosbellet et al. (2011) showed that when organic particles break down, they surround the aggregates already present in the soil with a fine film and protect them from degradation.

The relative increase in straw weight and grain yield with respect to control may be due to the beneficial effects of increasing organic matter in soil due to the application of soil amendments. This increase in straw weight and grain yield of wheat corresponded with improvement of physical properties (Table, 2 and Fig. 1). Similar results were obtained by Barzegar et al. (2002) and Aggag and Mahmoud (2006). The increase of grain yield with the application of vermicompost was attributed to the improving action of vermicompost on the soil physical properties as well as nutrients status in the soil, which enhances plant growth (El-Sanat, 2003). On the other hand, the highest straw weight and grain yield of wheat plants was observed

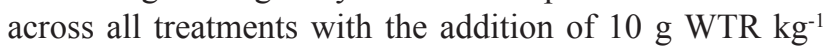
soil and $5 \mathrm{~g}(2 \mathrm{VC}+1 \mathrm{WTR}) \mathrm{kg}^{-1}$ soil treatments, compared with the addition of WTR alone at low level $\left(5 \mathrm{~g} \mathrm{~kg}^{-1}\right.$ soil). This may be due to the low fertilizer value of the WTR. Elliot and Dempsey (1990) showed that WTR generally had little fertilizer value. The addition of fertilizer and /or organic matter, such as compost, can help to improve nutritional value of the WTR. In our experiment, combination of VC and WTR improved the WTR efficiency in ameliorating the soil physical properties, which resulted in the best 
wheat yield. Very large amounts of WTR would have to be applied in order to markedly change the inherent soil physical properties and to improve wheat yield. However, high application rate of WTR $(>10 \%)$ causes a deficiency of plant available phosphorus, which results in reducing the plant growth (Dayton and Basta, 2001). Therefore, it is necessary to add fertilizer and/or organic matter to mitigate soil P deficiencies when WTR is reused actually as a growth medium (Park et al., 2010).

\section{CONCLUSIONS}

1. The results obtained indicate that the application of vermicompost alone or in combination with water treatment residuals confirmed its ability to improve the physical properties of the saline sodic soil and wheat yield.

2. Very large amounts of water treatment residuals would have to be applied in order to markedly change the inherent soil physical properties and to improve wheat yield.

3 . The application of vermicompost and water treatment residuals at ratio $2: 1$ at level of $5 \mathrm{~g} \mathrm{~kg}^{-1}$ soil gave the best wheat yield compared to other treatments.

4. Combination of vermicompost and water treatment residuals improved the water treatment residuals efficiency in ameliorating the soil physical properties, and could be considered as an ameliorating material to reclaim salt affected soils and to improve the yield of wheat. Moreover, it can be used as an economical and simple alternative for disposal methods of water treatment residuals.

\section{REFERENECS}

AFNOR, 1991. Matières Fertilisantes et Supports de Culture. Recueil des Normes Françaises. AFNOR, Paris, France.

Aggag A.M. and Mahmoud E.K., 2006. Influence of alum sludge and gypsum applications to improve soil quality and yield of wheat grown on salt - affected soils. J. Agric. Res. Tanta Univ., 4, 32-37.

Angin L., Aksakal E.L., Oztas T., and Hanay A., 2013. Effects of municipal solid waste compost (MSWC) application on certain physical properties of soilssubjected to freeze-thaw. Soil Till. Res., 130, 58-61.

Atiyeh R.M., Subler S., Edwards C.A., Bachman G., Metzger J.D., and Shuster W., 2000. Effects of vermicompost and composts on plant growth in horticultural container media and soil. Pedo Biologia, 44, 579-590.

Azarmi R.M., Giglou T., and Taleshmikail R.D., 2008. Influence of vermicompost on soil chemical and physical properties in tomato (Lycopersicum esculentum) field. African J. Biotechn., 7, 2397-2401.

Babatunde A.O. and Zhao Y.Q., 2007. Constructive approaches toward water treatment works sludge management: an international review of beneficial reuses. Crit. Rev. Environ. Sci. Technol., 37, 129-164.

Barzegar A.R., Yousef A., and Daryashenas A., 2002. The effect of addition of different amounts and types of organic materials on soil physical properties and yield of wheat. Plant Soil, 247, 295-301.
Benik P. and Bejbaruah R., 2004. Effect of vermicompost on rice (Oryza sativa) yield and soil-fertility status of rainfed humid sub-tropics. Indian J. Agric. Sci., 74, 488-491.

Blake G.F. and Hartge K.H., 1986. Bulk Density. In: Methods of Soil Analysis (Ed. A. Klute). Am. Soc. Agron., Madison,WI, USA.

Caravaca F., Masciandaro G., Ceccanti B., 2002. Land use in relation to soil chemical and biochemical properties in a Semiarid Mediterranean Environment. Soil Till. Res., 68, 23-30.

Dayton E.A. and Basta N.T., 2001. Characterization of drinking water treatment residuals for use as a soil substitute. Water Environ. Res., 73, 52-57.

De-Leenher L. and De-Boodt M., 1965. Soil Physics International Training Center for Post Graduate Soil Scientists, ITC-Ghent, Belgium.

Elliott H.A. and Dempsey B.A., 1990. Agronomic effects of land application of water treatment sludge. J. Am. Water Works Assoc., 83, 126-131.

El-Sanat G.M., 2003. Effect of amelioration processes on nutrients status in salt affected soils. M.Sc. Thesis, Fac. Agric., Menufiya Univ., Egypt.

Glenda S.I., Ismet B., Skender K., and Astrit B., 2009. The influence of vermicompost on plant growth characteristics of cucumber (Cucumis sativus L.) seedlings under saline conditions. J. Food Agric. Environ., 7, 869-872.

Grosbellet C., Vidal- Beaudet L.,Caubel V., and Charpentier S., 2011. Improvement of soil structure formation by degradation of coarse organic matter. Geoderma, 162, 27-38.

Ippolito J., Stromberger M., Barbarick K., and Bayley R., 2006. Water residuals and biosolids: effect of co-application on soil phosphorus. American Water Works Association IWA, USA.

Lordan J., Pascual M., and Fonseca F., 2013. Use of rice husk to enhance peach tree performance in soil switch limiting physical properties. Soil Till. Res., 129, 19-22.

Kalantari S., Hatami S., Ardalan M., Alikhani H.A., and Shorafa M., 2010. The effect of compost and vermicompost of yard leaf manure on growth of corn. African J. Agric. Res., 5, 1317-1323.

Kemper W.D. and Rosenau R.C., 1986. Aggregate stability and size distributio. In: Methods of Soil Analysis (Ed. A. Klute). Physical and Mineralogical Methods. ASA, SSSA, Madison, WI, Agronomy, 9, 425-442.

Kim H.T., 1996. Soil Sampling, Preparation, and Analysis. Dekker Press, New York, USA.

Klute A., 1986. Water retention. In: Methods of Soil Analysis. Physical and Mineralogical Methods (Ed. A. Klute). Agron. Monography, Madison, WI, USA.

Martens D.A. and Frankenberger W.T., 1992. Modification of infiltration rates in an organic-mended irrigated soil. Agron. J., 84, 707-717.

Mbah C.N. and Onweremadu E.U., 2009. Effect of organic and mineral fertilizer inputs on soil and maize grain yield in an acid Ultisol in Abakaliki Southeastern Nigeria. American Eurasian J. Agronomy, 2(1), 7-12.

Moodley M. and Hughes J.C., 2006. The effects of a polyacrylamide- derived water treatment residue on the hydraulic conductivity, water retention and evaporation of four contrasting South African soils and implications for land disposal. Water Sci. Techn., 54, 227-234. 
Moodley M., Johanston M.A., Hughes J.C., and Titshall L.W., 2004. Effects of water treatments residue, Lime, gypsum and polyacrylammide on the water rention and hydraulic conductivity of two contrasting soils under field conditions in Kawa Zulu-Natal. South Africa. Aust. J. Soil Res., 42, 273-282.

Nnaji G.U., 2009. Changes in physical properties of soil under cassava (Manihot esculenta Crantz) monocropping and organic waste amendments. Nat. Appl. Sci. J., 10, 12-17.

Oluwadare D.A. and Osakwe U.C., 2014. Effects of applied organic materials on physical properties of intensively cropped ultisol in North-Eastern Nigeria. J. Recent. Adv. Agri., 2, 199-207.

Pagliai M., Guidi G., La Marca M., Giachetti M., and Lucamante G., 1981. Effects of sewage sludge and composts on soil porosity and aggregation. J. Environ. Quality, 4, 556-561.

Park S.G., Yahata H., and Kurosawa K., 2010. Physical and chemical properties of water treatment residue and the characteristics of red pepper growth by using it. J. Fac. Agr. Kyushu Univ., 55, 117-122.

Qadir M. and Schubert S., 2002. Degradation processes and nutrient constraints in sodic soils. Land Degradation Develop., 13, 275-294.

Rhoades R.L., 1954. Diagnosis and improvement of saline and alkali soils. USDA Agriculture Handbook, No. 60 US Gov. Printing Office Washington, USA.

Romina R., Giuffré L., and Romero R., 2011. A soil quality index to evaluate the vermicompost amendments effects on soil properites. J. Environ. Protection, 2, 502-510.
SAS Institute, 1996. SAS/stat user's Guide version 6.4th ed SAS Institute Inc. Cary, NC, USA.

Seok-Gon P., Yahata H., Kurosawa K., and Hyun-Tak S., 2010. Physical and chemical properties of water treatment residue and the characteristics of red pepper growth by using it. J. Fac. Agr., Kyushu Univ., 55, 117-122.

Six J., Bossuyt H., Degryze S., and Denef K., 2004. A history of research on the link between (micro) aggregates, soil biota, and soil organic matter dynamics. Soil Till. Res., 79, 7-31.

Smith C.J., Bond W.J., and Wang W., 2000. Waste-free: vermicompost to improve agricultural soils, CSIRO. Land and Water: Colling Wood, Australia.Tech. Rep., 23, 14-19.

Suthar S., 2006. Effect of vermicompost and inorganic fertilizer on wheat (Triticum aestivum) production. Nature, Environ. Pollution Technol., 5, 197-201.

Šimon T., Mikanová O., and Cerhanová D., 2013. Long-term effect of straw and farmyard manure on soil organic matter in field experiment in the Czech Republic. Arch. Agron. Soil Sci., 59, 1193-1205.

Tisdall J.M. and Oades J.M., 1982. Organic matter and water stable aggregates in soils. J. Soil Sci., 33, 141-163.

Turner M.S., Clark G.A., Stanley C.D., and Smajstrla A.G., 1994. Physical characteristics of a sandy soil amended with municipal solid waste compost. Soil Crop Sci. Soc. Florida Proc., 53, 24-26.

Unagwu B.O., Asadu C.A., and Ezeaku P.I., 2013. Residual effects of organic and npk fertilizers performance at different soil pH levels. J. Agric. Vet. Sci., 5, 47-53. 